\title{
PEMBERDAYAAN MASYARAKAT MELALUI OPTIMALISASI PEMANFAATAN Trichoderma Sp SEBAGAI DEKOMPOSER LIMBAH SERASAH KARET DAN PERANANNYA DALAM MENGENDALIKAN PENYAKIT JAMUR AKAR PUTIH
}

\author{
"Prof. Dr. Ir. Reni Mayerni, MP., Dewi Rezki, SP.MP., Sri Heriza, SP, MSc \\ Staf Pengajar Fakultas Pertanian Universitas Andalas
}

\begin{abstract}
ABSTRAK
KKN PPM ini bertujuan untuk meningkatkan pengetahuan dan keterampilan Kelompok tani Tangkuban Perahu dan Kelompok tani Mekar melalui penyuluhan dan demonstrasi tentang penerapan teknologi pengendalian penyakit jamur akar putih pada tanaman karet di Kenagarian Tebing Tinggi dan Kenagarian Sungai Duo Kabupaten Dharmasraya. Metode kegiatan dilaksanakan dalam bentuk penyuluhan, pendampingan dan demontrasi plot. Respon dari mitra dalam kegiatan KKN PPM ini sangat positif dan memiliki animo yang tinggi untuk menerapkan teknogi pengendalian penyakit jamur akar putih pada tanaman karet. Petani juga antusias untuk melakukan pembuatan kompos sebagai alternatif penggunaan pupuk dan adanya peluang usaha yang baru. Adapun output dari kegiatan ini adalah teknologi pengendalian jamur akar putih dan pembuatan pupuk kompos limbah serasah. Setelah kegiatan ini dilakukan diharapkan mitra dapat menerapkan secara terus menerus dan dapat pula menyebarluaskan teknologi yang sudah diterima untuk diterapkan ke kelompok tani/ petani lainnya di kenagarian tersebut dan kenagarian lainnya.
\end{abstract}

Kata kunci: Pengendaian JAP, Karet, Kompos, Serasah, Trcihoderma sp

\section{ABSTRACT}

KKN PPM aims to increase knowledge and skill of Tangkuban Perahu farmer group and mekar sari farmer group through counseling and demonstration about the apllication of technology of white root fungus control on rubber plant in Kenagarian Tebing tinggi dan Sungai duo Kabupaten Dharmasraya. Methods of activities carried out in the form of counseling, mentoring and demonstration plot. Respons from patners in KKN PPM activity is very positive and has a high interest to apply teknologi control of white root fungus desease in rubber plants. Farmers are also enthusiastiec to make compost as an alternative to the use fertilizer and the existence of new business opportunities. The out put of this activity is the technology of white root fungus control and the manufacture of compost fertilizer waste litter. After this activy is expented partners can apply continuously and can also disseminate technology that has been accepted to apply to other farmers groups in the kenagarian and other kenagarian.

Keywords : JAP filling, Rubber, Compost, Litter, Trichoderma sp

\section{PENDAHULUAN}

Kabupaten Dharmasraya terletak pada posisi $0^{\circ} 47^{\prime} 7^{\prime \prime}-1^{\circ} 41^{\prime} 56^{\prime \prime}$ Lintang Selatan dan $101^{\circ} 9$ '21'”-101 54 '27" Bujur Timur. yang berada pada wilayah perbatasan Provinsi Sumatera Barat dengan Provinsi Jambi dan Provinsi Riau dan dilewati oleh Jalur Lintas
Tengah Sumatera. Kabupaten Dharmasraya terdiri dari 11 kecamatan, 52 nagari, dan 260 jorong. Kondisi dan Topografi wilayah Kabupaten Dharmasraya mayoritas merupakan lahan datar dengan Ketinggian dari 82 mdpl sampai 1.525 mdpl. Ketinggian terendah berada di wilayah Kecamatan IX 
Koto dan Ketinggian tertinggi berada di rangkaian Bukit Barisan yang melewati daerah Kabupaten Dharmasraya. Selama tahun 2015, rata-rata hari hujan mencapai 15,75 hari/bln di Sungai Rumbai,16,25 hari/bln di Koto Baru dan 16,92 hari/bln di Sitiung. Sedangkan rata-rata curah hujan mencapai 272,75 mm/bln di Sungai Rumbai, 249,00 mm/bln di Koto Baru dan 254,08 mm/bln di Sitiung (RKPD Kabupaten Dharmasraya, 2015).

Pengembangan tanaman perkebunan merupakan salah satu sektor primadona di Kabupaten Dharmasraya. Dua komoditi utama yang sedang berkembang pesat di Dharmasraya adalah tanaman karet dan kelapa sawit.

Masalah yang dihadapi petani di Kenagarian Sungai Duo dan Kenagarian Tebing Tinggi ini adalah masalah pupuk yang tidak tersedia sesuai dengan kebutuhan masyarakat. Sering terjadi kelangkaan pupuk karena pupuk subsidi hilang di pasaran, sehingga petani sulit untuk mempertahankan produksinya. Akhir - akhir ini pupuk subsidi tidak dapat memenuhi kebutuhan petani akan pupuk. Apalagi ditambah rencana pemerintah untuk mengurangi/ menghapus subsidi pupuk secara bertahap, maka petani akan kesulitan untuk memenuhi kebutuhan pupuknya. Masalah lain yang dihadapi oleh petani adalah tingginya tingkat serangan jamur akar putih pada tanaman karet petani, sehingga tanaman karet banyak yang mati.
Salah satu alternatif yang dapat memecahkan masalah kelangkaan pupuk adalah menggunakan pupuk organik dari limbah pertanian. Pembuatan kompos itu sederhana dan mudah dipraktekkan asal mau, tekun dan memiliki inovasi. Untuk beralih ke pupuk organik ini perlu sosialisasi terus menerus karena petani terbiasa menggunakan pupuk kimia yang bersifat instan.

Pupuk kompos dapat berasal dari sampah organik yang telah mengalami dekomposisi akibat adanya interaksi mikroorganisme di dalamnya. Bahan bahan organik yang digunakan antara lain dedaunan, serasah karet, rumput, jerami, kotoran hewan dan sampah (Rezki, 2015).

Dilihat dari produktivitas karet petani di Kenagarian Sungai Duo dan Kenagarian Tebing Tinggi masih tergolong rendah yaitu rata-rata produksi karet 0,8 ton/Ha, jika dibandingkan dengan prduktivitas tanaman karet yang dibudidayakan dengan tindak budidaya yang benar dapat mencapai 2 ton/Ha, Rendahnya produktivitas karet rakyat secara umum disebabkan oleh pengelolaan perkebunan karet rakyat masih belum mengikuti petunjuk budidaya yang benar.

Petani belum melakukan kegiatan pemeliharaan tanaman yang baik dan benar, seperti kurangnya pemupukan dan pengendalian hama dan penyakit. Hal ini terindikasi dari tingginya tingkat serangan penyakit terutama penyakit Jamur Akar Putih (JAP) sekitar $30 \%$. Penyakit JAP menimbulkan kematian pada tanaman karet, 
sehingga serangan penyakit ini akan berpengaruh negatif pada produksi kebun. Penyakit JAP ini dapat dikendalikan dengan mengaplikasikan Trichoderma sp pada area perakaran tanaman yang terserang.

Kelompok tani Tangkuban Perahu adalah kelompok tani yang terdapat di Kenagarian Sungai Duo Kecamatan Sitiung dan Tani Mekar adalah kelompok tani karet yang terdapat di Kenagarian Tebing Tinggi Kecamatan Pulau Punjung. Tanaman karet pada beberapa kelompok ini banyak terserang penyakit jamur akar putih (JAP) yang disebabkan oleh jamur Rigidiporus microporus atau Rigidoporus lignosus yang sulit dikendalikan oleh petani karena menyerang sistem perakaran tanaman karet, Akar tanaman yang terserang terlihat adanya misellia jamur yang berbentuk benang, berwarna putih yang menempel kuat dan sulit dilepaskan dari akar tanaman. Akar tanaman yang terinfeksi akan menjadi lunak, membusuk dan berwarna coklat. Gejala serangan penyakit tampak dari memucatnya daun-daun dengan tepi ujung terlipat ke dalam. Daun-daun tersebut selanjutnya gugur dan ujung rantingnya mati, dalam waktu 6 sampai 1 tahun serangan tanaman akan mati. Penggunaan bibit unggul yang sehat serta penjagaan kebersihan kebun dari sisa-sisa tunggul dan akar tanaman lama, pemeliharaan tanaman yang intensif merupakan cara yang dapat mencegah/ preventif ternyadinya serangan JAP.

Petani dalam mengendalikan penyakit
JAP hanya menggunakan cara konvensional yaitu dengan membuka tanah pada bagian leher akar dengan membuat lubang berjarak $30 \mathrm{~cm}$ di sekeliling akar. Lalu benang-benang jamur yang masih menempel pada akar dikerok atau akar yang diserang berat dipotong dan dimusnahkan selanjutnya diolesi dengan ter. Kemudian akar tersebut ditutup kembali dengan tanah. Pengendalikan JAP seperti ini selain membutuhkan tenaga kerja dan waktu serta dana yang dibutuhkan banyak juga tidak efektif dan hanya dilakukan pada tanaman yang telah terserang berat sehingga kemungkinan penyebaran penyakit JAP ini di kebun masyarakat akan tetap bertahan. Lemahnya tindakan budidaya tanaman karet oleh anggota kelompok tani terutama dalam pengendalian penyakit JAP diantaranya disebabkan oleh kurangnya pengetahuan petani terhadap teknologi yang efektif dan efisien didalam pengendalian penyakit JAP. Dengan demikian perlu diberikan peningkatan pengetahuan petani terhadap teknologi tersebut. Sementara itu, Amaria (2015) menyatakan bahwa Trichoderma sp mampu menghambat perkembangan penyakit jamur akar putih pada tanaman karet melalui mekanisme kompetisi, antibiosis, atau parasitisme.

Tujuan dari kegiatan pengabdian pada masyarakat ini adalah untuk menambah pengetahuan dan keterampilan petani mengenai manfaat Trichoderma $s p$ dalam budidaya tanaman karet yang benar secara umum dan khususnya teknologi pembuatan 
kompos dan pengendalian penyakit jamur akar putih secara terpadu, agar dihasilkan kebun karet yang sehat dan pertanian yang berkelanjutan di Kenagarian Sungai Duo dan kenagarian Tebing Tinggi.

Berdasarkan diskusi dan kesepakatan antara tim pengabdian dengan mitra, kegiatan dilakukan dalam bentuk penyuluhan dan demplot. Metode penyuluhan dilakukan dengan menggunakan metode pendidikan orang dewasa (andragogi), yaitu ceramah dan diskusi.

Materi penyuluhan yang diberikan adalah :

$\checkmark$ Manfaat Trichoderma $s p$ bagi dunia pertanian dan cara perbanyakannya

$\checkmark$ Cara perbanyakan Trichoderma $s p$

$\checkmark$ Cara pembuatan kompos dari limbah serasah yang baik dan benar

$\checkmark$ Deskripsi penyakit jamur akar putih (JAP) dan teknologi pengendalian JAP menggunakan Trichoderma $s p$

$\checkmark$ Pengenalan tanaman antagonis untuk pengendalian JAP

Kegiatan Demplot yang dilakukan adalah:

Melakukan perbanyakan Trichoderma sp

$\checkmark$ Pembuatan kompos dari limbah serasah dan gulma menggunakan dekomposer Trichoderma $s p$ sp. yang selanjutnya diaplikasikan pada tanaman karet

$\checkmark$ Mengidentifikasi penyakit JAP dilapangan (kebun petani), dan penentuan tingkat serangan penyakit dan cara teknologi pengendalian yang tepat.

$\checkmark$ Aplikasi Trichoderma sp untuk mengendalikan jamur akar putih pada tanaman karet.

\section{METODE PELAKSANAAN}

Pelaksanaan program KKN-PPM dilakukan dengan melibatkan masyarakat setempat dan mahasiswa menjadi fasilitator. Metode yang dilakukan adalah penyuluhan, pelatihan, demonstrasi, praktek teknologi pengolahan dan pendampingan.

Seluruh kegiatan melibatkan berbagai pihak antara lain mahasiswa KKN - PPM Unand, Dinas Pertanian Kabupaten Dharmasraya, Wali nagari Sungai Duo Kecamatan Sitiung dan Wali nagari Tebing Tinggi Kecamatan Pulau Punjung, pihak terkait lainnya sebagai narasumber sesuai topik kegiatan.

Program ini merupakan alih teknologi dan pendampingan oleh mahasiswa. Kegiatan-kegiatan KKN-PPM yang akan dilakukan adalah sebagai berikut:

a. Penyuluhan perbanyakan Trichoderma $s p$

b. Pelatihan dan pembuatan kompos dari limbah pertanian.

c. Demonstrasi aplikasi pupuk kompos pada tanaman karet

d. Penyuluhan identifikasi penyakit jamur akar putih

e. Demonstrasi aplikasi Trichoderma $s p$ dalam mengendalikan jamur akar putih.

\section{HASIL DAN PEMBAHASAN}

\section{Perbanyakan Jamur Trichoderma sp Skala} Petani

Mahasiswa KKN PPM bersama dengan Kelompok tani Tangkuban Perahu di 
Kenagarian Tebing Tinggi melakukan tim pengabdian di lokasi kelompok tani perbanyakan Trichoderma sp. Bahan dan tangkuban perahu. Semua anggota kelompok alat yang dibutuhkan dalam perbanyakan tani dengan antusias mengikuti kegiatan jamur Trichoderma dengan menggunakan perbanyakan tersebut. Teknologi media nasi adalah: Biang Trichoderma, pengendalian penyakit tanaman karet dengan Beras, Air, Box Isolasi, Kompor, Panci/ menggunakan agens hayati cendawan Dandang, Baskom, Sendok, Plastik bening Trichoderma sp. Sangat menarik perhatian ukuran $1 \mathrm{~kg}$, dll.

Kegiatan demontrasi perbanyakan jamur Trichoderma ini didemokan langsung oleh mitra, karena teknik perbanyakan cendawan Trichoderma sp. secara langsung baru pertama kali mereka lihat (Gambar 1).
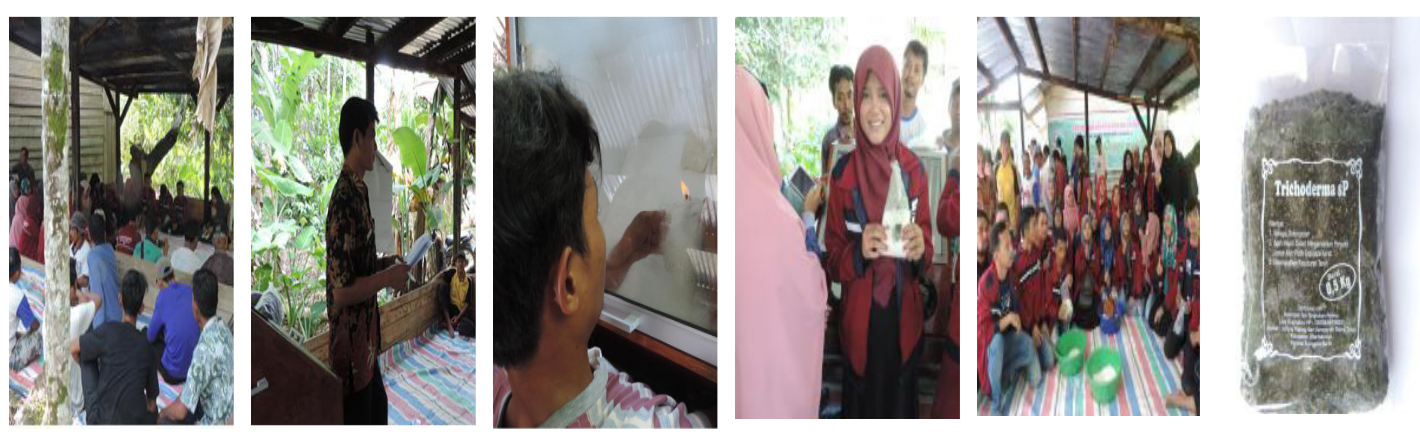

Gambar 1. Perbanyakan Trichoderma sp yang dilaksanakan Tim KKN PPM dengan Kelompok Tani Tangkuban Perahu di Kenagarian Tebing Tinggi

Pengendalian Penyakit Jamur Akar Putih (JAP) pada Tanaman Karet melalui

\section{Aplikasi Trichoderma sp}

Tim KKN PPM memperkenalkan kepada anggota kelompok tani tangkuban perahu cara mengidentifikasi serangan penyakit JAP dan cara pengendaliannya. Metode pengendalian secara biologis dengan pemanfaatan Trichoderma sp sebagai musuh alami merupakan alternatif yang tepat untuk mengendalikan beberapa penyakit penting perkebunan seperti penyakit JAP pada tanaman karet. Keuntungan Aplikasi Trichoderma adalah aplikasinya mudah, murah dan efek perlakuan bersifat laten serta tidak menimbulkan keracunan atau pencemaran lingkungan. Trichoderma juga dapat bertahan lama dan berkembang pada bahan organik tanah sebagai media tempat hidupnya.

Dosis pemakaian Trichoderma sp yang diaplikasikan dilahan karet milik anggota kelompok tani tangkuban perahu adalah 100 g/pohon. Petani sangant merasakan manfaat dari kegiatan ini, karena selama ini pengetahuan petani mengenai penyakit JAP pada karet dan cara pengendaliannya sangat minim (Gambar 2). 

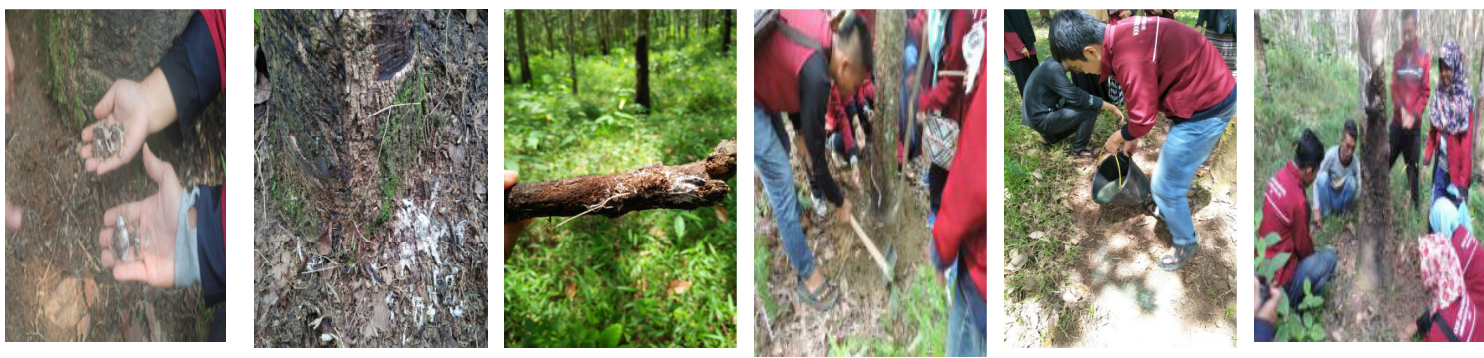

Gambar 2. Identifikasi dan aplikasi Trichodermasp yang dilaksanakan Tim KKN PPM dengan Kelompok Tani Tangkuban Perahu di Kenagarian Tebing Tinggi

Pembuatan Kompos Limbah Serasah Menggunakan Trichoderma sp sebagai

\section{Dekomposer}

Limbah serasah merupakan bahan organik yang berasal dari daun-daun pohon karet yang gugur, rumput, ranting dan bahan organik lainnya yang menutupi tanah perkebunan karet tersebut. Bahan-bahan organik yang digunakan antara lain dedaunan, serasah karet, rumput, jerami, kotoran hewan dan sampah. Tertutupnya permukaan tanah oleh limbah serasah akan memicu pertumbuhan Jamur Akar Putih (JAP) pada perakaran tanaman karet, jamur ini akan menginfeksi karet dan menyebabkan tanaman karet tersebut menjadi mati. Namun, dengan membuat limbah serasah menjadi
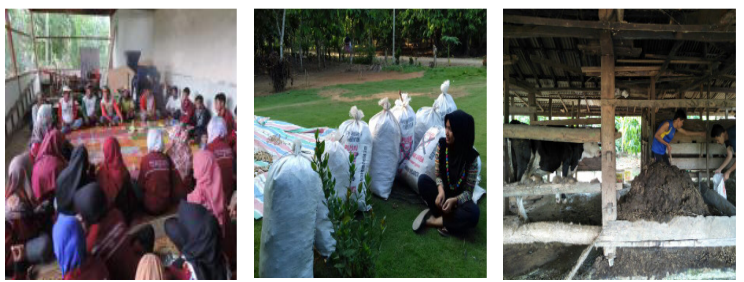

kompos akan memberikan nilai tambah bagi petani.

Bahan dan alat yang dibutuhkan dalam pembuatan kompos dari limbah serasah karet adalah limbah serasah, pupuk kandang, Trichoderma sp, abu/kapur, air, mesin pencacah, cangkul, terpal, dll. Tim KKN PPM melakukan demonstrasi dan pelatihan langsung kepada anggota kelompok tani mekar. Petani sangat antusias melakukan kegiatan ini, karena limbah-limbah tersebut biasanya hanya dibuang, sedangkan sekarang petani bisa mengolah limbah tersebut dan mempunyai peluang usaha baru. Kegiatan pembuatan kompos dapat dilihat pada Gambar 3.
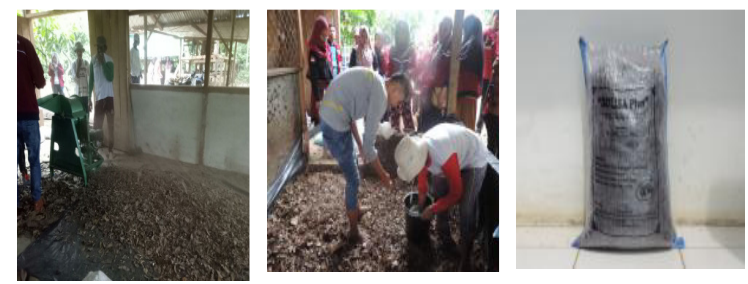

Gambar 3. Pembuatan kompos limbah serasah dengan menggunakan Trichoderma sp sebagai dekomposer

Proses dekomposisi kompos limbah terdekomposisi sempurna adalah kompos serasah berlangsung selama satu bulan. Ciri- tidak berbau, tidak terasa panas, bentuk asal ciri kompos limbah serasah yang sudah limbah serasah sudah tidak terlihat dan 
bentuk komposnya sudah granular. Kompos yang sudah matang di ayak menggunakan ayakan dengan ukuran 2 mesh, agar ukuran kompos menjadi seragam. Kompos di analisis dilaboratorium untuk mengetahui jumlah kandungan hara yang ada pada kompos. Hasil analisa laboratorium dapat dilihat pada Tabel 1.

Tabel 1. Hasil analisa pupuk kompos limbah serasah

\begin{tabular}{lllll}
\hline $\mathrm{pH}$ & N-total $(\%)$ & C-organik $(\%)$ & $\mathrm{P} 2 \mathrm{O} 5(\mathrm{mg} / 100 \mathrm{~g})$ & $\mathrm{K} 2 \mathrm{O}(\mathrm{me} / 100 \mathrm{~g})$ \\
\hline $6,9 *$ & $1,40^{*}$ & $22^{*}$ & $14,12^{*}$ & $0,21^{*}$ \\
$6,8-7,4^{* *}$ & $9,8-32^{* *}$ & $0,4^{* *}$ & $10-20^{* *}$ & $0,2^{* *}$ \\
\hline
\end{tabular}

Keterangan : *) Hasil analisa pupuk bokashi yang digunakan dalam penelitian ini

**) Kriteria mutu pupuk organik domestik berstandar SNI 19-7030-2004

Pada Tabel 1 menunjukkan bahwa pupuk organik domestik berstandar SNI. analisa pupuk kompos yang telah dibuat

Setelah pembuatan kompos limbah memiliki nilai $\mathrm{pH}$ 6,9, N-total 1,4, C-Organik serasah dilakukan, maka kompos yang sudah $22 \%$, P2O5 14,12 mg/100 g dan K2O 0,21 terdekomposisi secara sempurna me/100 g. Sementara itu, berdasarkan diaplikasikan oleh tim KKN PPM bersamaspesifikasi kriteria mutu pupuk organik sama dengan petani kelahan karet milik domestik menurut Badan Standarisasi anggota kelompok tani mekar. Aplikasi ini Nasional Tahun 2004 dengan No SNI 19-703 bertujuan untuk menambah unsur hara yang 0-2004 adalah pH 6,8-7,4, C-organik 9,8-32 dibutuhkan oleh tanaman karet. Selain itu, $\%$, N-total 0,4\%, P2O5 10-20 mg/100 g dan aplikasi kompos yang mengandung jamur 0,2 me/100 g. Dengan demikian dapat Trichoderma sp juga bisa mengantisipasi dinyatakan bahwa kompos yang telah dibuat serangan penyakit JAP pada karet. Kegiatan oleh petani dan mahasiswa dalam kegiatan aplikasi kompos dapat dilihat pada Gambar KKN PPM sudah memenuhi kriteria mutu
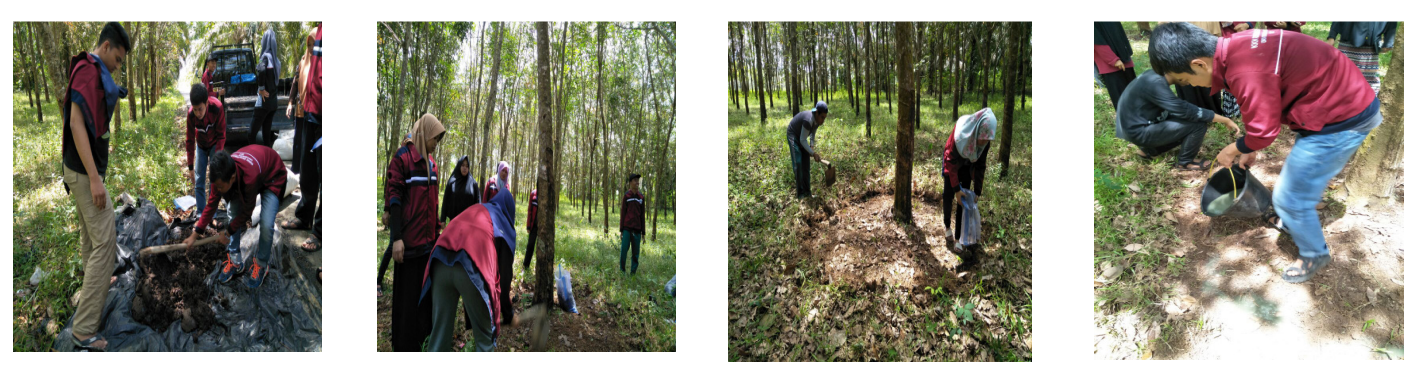

Gambar 4. Aplikasi kompos limbah serasah 


\section{KESIMPULAN DAN SARAN}

Kelompok tani Tangkuban Perahu dan Kelompok Tani Mekar memiliki respon yang sangat positif terhadap kegiatan KKN PPM ini. Hal ini dapat dilihat dari semua kegiatan yang telah dilakukan,mitra kedua kelompok tani berperan aktif dalam kegiatan KKN PPM ini. Masing-masing kelompok tani sangat tertarik dan menyatakan bahwa materi penyuluhan sangat mereka butuhkan dalam pengendalian penyakit JAP pada tanaman karet.

\section{UCAPAN TERIMAKASIH}

Terima kasih diucapkan kepada Kementerian Riset dan Pendidikan Tinggi yang telah membiayai kegiatan pengabdian ini melalui dana DIPA DPRM, sesuai dengan surat perjanjian pelaksanaan kegiatan Nomor : 012/SP2H/PPM/DPRM/2017. Terima kasih juga kami ucapkan kepada LPPM Universitas
Andalas, yang telah mendukung kegiatan KKN PPM ini. Serta semua pihak yang telah banyak membantu sehingga selesainya kegiatan KKN PPM ini.

\section{DAFTAR PUSTAKA}

Amaria, W, Harni, R dan Samsudin, 2015. Evaluasi jamur antagonis dalam mengahambat pertumbuhan rigidoporus microporus penyakit jamur akar putih pada tanaman karet. Jurnal Tanaman Industri dan Penyegar. Vol 2 No 1.

Badan Standarisasi Nasional, 2014. Spesifikasi kompos dari sampah organik domestik.

Rezki, D. 2015. Pengaruh penambahan bokashi dari limbah pertanian terhadap pertumbuhan tanaman padi dengan jajar legowo. Laporan pendampingan upsus padi, jagung dan kedelai. 